\title{
Local Versus Systemic Use of Tranexamic Acid in Elective Cesarean Section
}

\author{
KAREEM A. ABDULLATIF HASSAN, M.Sc.; MOHAMED A. ELNEGERI, M.D. and \\ MAHER SHAMS ELDIN HASSAN, M.D. \\ The Department of Obstetrics \& Gynecology, Faculty of Medicine, Mansoura University, Egypt
}

\begin{abstract}
Background: Obstetric hemorrhage remains one of the major determinants of maternal death in both developed and developing countries. Because of its weight as a leading cause of maternal mortality and morbidity. Hemostatic drugs are not usually used as first-line treatment in post-partum hemorrhage (PPH). It was authenticated that extensive tissue injury can direct the hemostatic equilibrium toward increased fibrinolysis, leading to coagulopathy and bleeding. Antifibrinolytic drugs, named tranexamic acid (TXA) have been recognized to decrease blood loss and transfusion needs in various elective surgeries.
\end{abstract}

Aim of Study: Evaluating the role of adjunctive IV Tranexamic acid versus topical Tranexamic acid infusion of the placental bed to prevent the postpartum hemorrhage.

Patients and Method: It was a randomized clinical trial that extended from January 2019 to January 2020 and was done at Mansoura University Hospital, Obstetrics and Gynecology Department and it included a total of 164 pregnant subjects planning for cesarean section who were randomly divided into two groups; the initial group included cases who were subjected to local tranexamic acid administration (2gm), and the other one included cases who were commenced on the intravenous form (1gm). Before operation, all subjects were subjected to complete history taking, fulllaboratory investigations, detailed obstetric examination, and pelviabdominal ultrasound. Cesarean section was performed in all cases using the standard procedure.

Results: The mean age of the included cases was 35.3 and 33.89 years in the local and systemic groups respectively. There was no significant difference between the two groups regarding parity, number of gestations, the indication of cesarean section and the mean operative time. Blood loss was significantly increased in the systemic group versus local group $(p<0.001)$, hemoglobin levels showed significant decrease in the systemic group. The change in both hemoglobin and hematocrit levels was significantly higher in the systemic group $(p<0.001)$.

Conclusion: It is apparent that topical administration of TXA is associated with more effective to decrease blood loss

Correspondence to: Dr. Kareem A. Abdullatif Hassan, The Department of Obstetrics \& Gynecology, Faculty of Medicine, Mansoura University, Egypt and causes less change in hematological parameters compared to its intravenous administration.

Key Words: Postpartum hemorrhage - Tranexamic acid Maternal mortality.

\section{Introduction}

AN obstetric hemorrhage may occur before or after delivery, but more than $80 \%$ of cases occur postpartum [1]. This type of hemorrhage is responsible for $25 \%$ of the deaths of an estimated 358000 women worldwide each year [2,3]. The overwhelming majority die in resource-poor countries, but an unacceptable number of these women die in resource-rich countries [2,4]. Many deaths occur because of a poor clinical response to massive bleeding and while in many countries this reflects a scarcity of resources, trained personnel, and access to basic health care, even when these are present, there is often a failure to coordinate the management of emergency resuscitation procedures. A concerted effort is required in every country and community to optimize care with available resources and identify where improvements can be made [2] . Reducing mortality and morbidity in obstetric patients presents challenges at each end of the coagulation spectrum. The greatest cause of maternal mortality worldwide is from hemorrhage [5].

Pharmacologic manipulation of the coagulation cascade, including the use of the antifibrinolytic tranexamic acid, has become an important part of reducing hemorrhage risk in obstetric patients. This antifibrinolytic lysine analog was first synthesized in 1962 for use in the treatment of postpartum hemorrhage [6]. It serves as a competitive inhibitor of plasminogen activation and has been shown to be effective when employed as a prophylactic hemorrhage reduction strategy in numerous 
randomized, controlled trials [7]. Obstetric hemorrhage has unique features that have limited the generalizability of pharmacologic management strategies from non-obstetric settings. On one hand, the higher baseline prevalence of thromboembolism made the use of tranexamic acid unattractive in obstetric patients, but conversely, the disproportional coagulopathy observed relative to total blood loss when compared with surgical or traumatic hemorrhage made it appear to perhaps be a welcome intervention [8]. It was concluded that the main advantage of using tranexamic acid during elective cesarean section and the immediate postpartum period is reducing the amount of placental site hemorrhage. On the other hand, several safety considerations have become evident related to tranexamic acid administration recently. Firstly, there have been reported serious thromboembolic events related to its administration that warrant attention [9].

A second safety concern has manifest in highly consequential drug substitution errors. There have been several reported cases of maternal death following the intrathecal administration of tranexamic acid in obstetrics [10]. Unfortunately, some $2 \mathrm{~mL}(500 \mathrm{mg})$ vials of tranexamic acid are remarkably similar to vials of bupivacaine that are administered for spinal anesthesia for cesarean delivery. There are few drug substitutions errors that have been as uniformly lethal as injecting one half of a gram of tranexamic acid into the cerebrospinal fluid. Perhaps the most important element of increasing use of tranexamic acid would be to ensure that systems are in place for safe administration to avoid such similar tragedies. A third known complication of tranexamic acid is seizure activity. Tranexamic acid is a competitive antagonist of gamma-aminobutyric acid (GABA), which reduces the inhibition of neurotransmission thus increases excitability in neural networks. Dose dependent seizure activity has been reported with an incidence of $0.9-2.5 \%$ in non-obstetric patients, but this effect has generally not been observed with to the same degree in pregnant patients for unclear reasons [11]. So, this study was done to Evaluate the role of adjunctive IV Tranexamic acid versus topical Tranexamic acid infusion of the placental bed to prevent the postpartum hemorrhage.

\section{Patients and Methods}

Study:

This was a randomized clinical trial that extended from January 2019 to January 2020 and was done at Mansoura University Hospital, Obstetrics and Gynecology Department. The Sample size calculation was based on mean blood loss amount after operationdepending on pilot study on 20 patients. Using $\mathrm{G}$ power calculator to calculate difference between 2 means using $t$-test with means (123.05 \& 130.15) and SD (17.56 \& 14.48), 2tailed, with a error $=0.05$ and power $=80.0 \%$. The total calculated sample size will be 82 for each group with calculated effect size (0.44).

\section{Patients:}

We included pregnant ladies in 3 rd trimester whose plan is to deliver by elective cesarean section and pregnant women in 3 rd trimester who have obstetric indication for repeat cesarean section but we excluded emergent cases delivered by emergent cesarean section and patients with history of drug allergy from tranexamic acid. This study included 164 pregnant patients whom had delivery by elective cesarean section after taking their written consent for undergoing elective cesarean section with giving them tranexamic acid after informing them with possible complications. We divided them into two groups by numerical randomization after informed consent.

First group (Intravenous tranexamic acid group) had taken infusion containing $1 \mathrm{~g}(10 \mathrm{ml})$ tranexamic acid diluted with $20 \mathrm{ml}$ of $5 \%$ glucose administered intravenously over a 5-minute period at least 10 minutes prior to skin incision.

Second group (Topical tranexamic acid group) had received $2 \mathrm{gm}(20 \mathrm{ml})$ topical tranexamic acid after placental delivery applied on placental bed by using a sterile towel soaked with $2 \mathrm{~g}$ Tranexamic acid $(20 \mathrm{ml})$ diluted in $100 \mathrm{ml}$ of sodium chloride $0.9 \%$.

After delivery, both groups received a 5IU intravenous bolus of oxytocin, and then 30IU oxytocin in $500 \mathrm{~mL}$ lactated Ringer's solution that was infused at a rate of $125 \mathrm{~mL} / \mathrm{h}$. An antibiotic, $1 \mathrm{~g}$ of antibiotic diluted in $20 \mathrm{~mL}$ normal saline, was administered over a 5-minute period. Vital signs (heart rate, blood pressure, and respiratory rate) had been checked and noted before the operation, immediately after placental delivery, and 1 and 2 hours after birth.

Prothrombin time (PT) activated partial prothrombin time (aPTT), and complete blood count (CBC) had been documented before delivery and on the second day after delivery. Estimated blood loss was calculated by the difference in hematocrit values taken prior to and 48 hour after cesarean delivery, according to the following formula: EBV (estimated blood volume $)=$ Body wt $(\mathrm{kg}) \mathrm{x}$ average 
blood volume (ml/kg), Estimated blood loss = EBV $\mathrm{x}$ (Hi-Hf)]/Hi, where EBV = Estimated Blood Volume, $\mathrm{Hi}=$ Initial hematocrit, $\mathrm{Hf}=$ Final hematocrit, Average blood volumes in adult Women $65 \mathrm{~mL} / \mathrm{kg}$, Blood loss $>1000 \mathrm{~mL}$ during the procedure will be defined as excessive bleeding.

After discharge, women whom received TA were instructed about the signs and symptoms of a thromboembolic events, and they had followupcard with written instruction sheets for symptom documentation and were instructed to contact the department.

\section{Statistical analysis:}

IBM's SPSS statistics (Statistical Package for the Social Sciences) for windows (version 25, 2017) was used for statistical analysis of the collected data. Shapiro-Wilk test was used to check the normality of the data distribution. All tests were conducted with $95 \%$ confidence interval. $p$ (probability) value $<0.05$ was considered statistically significant. Charts were generated using SPSS' chart builder and Microsoft Excel for windows 2019.

Descriptive: Quantitative variables were expressed as mean and standard deviation while categorical variables were expressed as frequency and percentage.

Continuous Group differences: Independent sample $t$ and Mann Whitney tests were used for inter-group (between subjects) comparison of parametric and non-parametric continuous data respectively, For pair-wise comparison of data (within subjects), the follow-up values were compared to their corresponding basal value using paired samples $t$-test, Wilcoxon matched pairs signed ranks test or related-samples Friedman's two-way analysis of variance by ranks with Bonferroni correction of $p$-value for multiple comparisons.

Categorical Group differences: Fisher exact and Chi square tests were used for inter-group comparison of nominal data using the cross-tab's function.

\section{Results}

The mean age of the included cases was 35.3 and 33.89 years in the local and systemic groups, respectively. BMI had mean values of 28.49 and $28.98 \mathrm{~kg} / \mathrm{m}^{2}$ in the two groups, respectively. Neither of the previous variables appeared to be statistically significant when comparing the two groups $(p=0.15$ and 0.267 respectively). Regarding obstetric history, the included females had mean parity of 1.74 and
1.77, while gestations had mean values of 2.73 and 2.72 in the two groups, respectively. The gestational age of the included cases was 36.96 and 36.93 weeks in the same groups, respectively. No significant difference was detected between the two groups regarding the previous three parameters (Table 1).

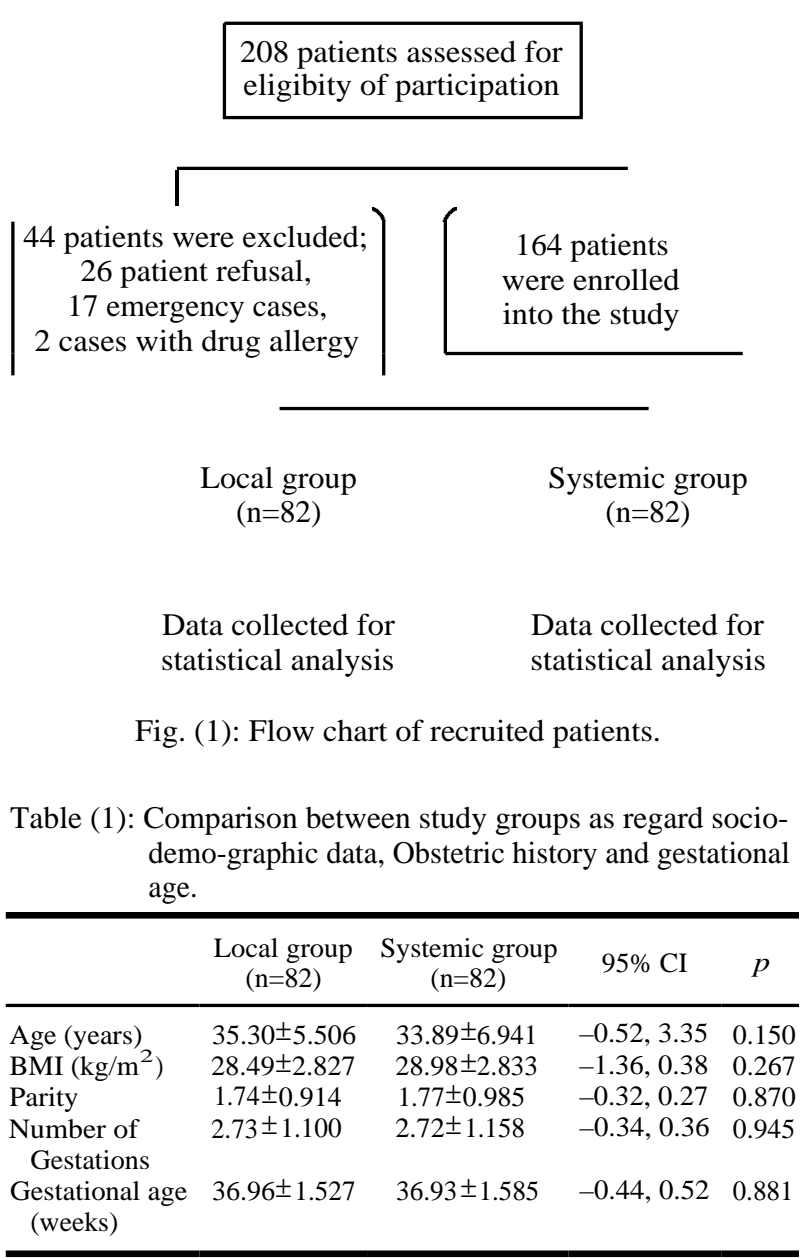

Data is expressed as mean and standard deviation.

CI: Confidence interval of the mean difference between both groups. $p$ is significant when $<0.05$.

There was no different difference between the two groups regarding the indication of cesarean section. Previous CS was the commonest indication in both groups, as it was reported in 53.7 and $52.4 \%$ of cases in the local and systemic groups, respectively. Other causes included diabetes, preeclampsia, infertility, abnormal presentation, twin pregnancy, low lying placenta, abnormal liquor, fetal distress, and CPD (Table 2).

When it comes to operative details, the mean operative time was 6.59 and 48.48 minutes in the two groups, respectively. No significant difference was detected between the two groups regarding that parameter $(p=0.143)$. Blood in the suction jar 
had mean values of 274.7 and $332.32 \mathrm{ml}$, whereas estimated blood loss had mean values of 691.46 and $746.04 \mathrm{ml}$ in the two groups, respectively. Blood loss was significantly increased in the systemic group versus local group $(p<0.001)$. Although there was no significant difference between the two groups regarding preoperative hemoglobin levels $(p=0.351)$, there was a significant decrease in it in the systemic group $(9.82 \mathrm{vs} .10 .15 \mathrm{gm} / \mathrm{dl}$ $p=0.001)$. The same pattern was also noted in the hematocrit value $(p=0.025)$. The change in both hemoglobin and hematocrit levels was significantly higher in the systemic group ( $p=0.008$ and 0.032 respectively) (Table 3 ).

When comparing hemoglobin and hematocrit value in an individual group, there was a significant decrease in both groups $(p<0.001)$ (Table 4). Blood transfusion was needed in 7.3 and $17.1 \%$ of cases in the two groups, respectively ( $p=0.056)$. Addi- tionally, the duration of hospitalization did not significantly differ between the two groups $(29.56$ vs. 27.07 in the two groups, respectively $-p=0.07$ ) (Table 5).

Table (2): Indications of CS in the studied groups.

\begin{tabular}{llll}
\hline & $\begin{array}{c}\text { Local group } \\
(\mathrm{n}=82)\end{array}$ & $\begin{array}{c}\text { Systemic group } \\
(\mathrm{n}=82)\end{array}$ & $p$ \\
\hline Diabetes Miletus & $2.4 \%(2)$ & $3.7 \%(3)$ & \\
Hypertension/preeclampsia & $9.8 \%(8)$ & $11.0 \%(9)$ & \\
Infertility & $6.1 \%(5)$ & $4.9 \%(4)$ & \\
Abnormal Presentation & $6.1 \%(5)$ & $4.9 \%(4)$ & \\
Twins & $2.4 \%(2)$ & $4.9 \%(4)$ & \\
Previous CS & $53.7 \%(44)$ & $52.4 \%(43)$ & 0.995 \\
Low-lying placenta & $4.9 \%(4)$ & $6.1 \%(5)$ & \\
Abnormal Liquor & $7.3 \%(6)$ & $7.3 \%(6)$ & \\
Fetal distress & $4.9 \%(4)$ & $2.4 \%(2)$ & \\
CPD & $2.4 \%(2)$ & $2.4 \%(2)$ & \\
\hline
\end{tabular}

Data is expressed as percentage and frequency. $p$ is significant when $<0.05$.

Table (3): Duration of surgery, amount of blood loss, Basal and post-operative hemoglobin and hematocrit values in both groups.

\begin{tabular}{lllll}
\hline & $\begin{array}{c}\text { Local group } \\
(\mathrm{n}=82)\end{array}$ & $\begin{array}{c}\text { Systemic group } \\
(\mathrm{n}=82)\end{array}$ & 95\% CI & $p$ \\
\hline Operative duration (minutes) & $46.59 \pm 8.122$ & $48.48 \pm 8.340$ & $-4.43,0.65$ & 0.143 \\
Blood in suction jar (ml) & $274.70 \pm 42.400$ & $332.32 \pm 50.688$ & $-72.03,-43.21$ & $<0.001$ \\
Estimated blood loss (ml) & $691.46 \pm 69.746$ & $746.04 \pm 59.248$ & $-74.53,-34.62$ & $<0.001$ \\
Basal HB (gm/d) & $11.96 \pm 0.940$ & $12.08 \pm 0.742$ & $-0.38,0.14$ & 0.351 \\
Post-operative HB (gm/dl) & $10.15 \pm 0.632$ & $9.82 \pm 0.658$ & $0.13,0.53$ & 0.001 \\
HB change (gm) & $-1.80 \pm 1.174$ & $-2.26 \pm 1.001$ & $0.12,0.79$ & 0.008 \\
Basal HTC (\%) & $33.83 \pm 1.460$ & $33.91 \pm 1.440$ & $-0.53,0.36$ & 0.703 \\
Post-operative HTC (\%) & $32.66 \pm 1.853$ & $31.97 \pm 2.037$ & $0.09,1.29$ & 0.025 \\
HTC change $(\%)$ & $-1.17 \pm 2.343$ & $-1.94 \pm 2.235$ & $0.07,1.48$ & 0.032 \\
\hline
\end{tabular}

Data is expressed as mean and standard deviation or as percentage and frequency.

CI: Confidence interval of the mean difference between both groups.

$p$ is significant when $<0.05$.

Table (4): Comparison of basal and post-operative hemoglobin and hematocrit values in both groups.

\begin{tabular}{lcccccccc}
\hline & \multicolumn{3}{c}{ Local group $(\mathrm{n}=82)$} & & \multicolumn{3}{c}{ Systemic group (n=82) } \\
\cline { 2 - 3 } & Pre & Post & $p$ & & Pre & Post & $p$ \\
\hline Hemoglobin & $11.96 \pm 0.940$ & $10.15 \pm 0.632$ & $<0.001$ & & $11.88 \pm 0.742$ & $9.82 \pm 0.658$ & $<0.001$ \\
Hematocrit & $33.83 \pm 1.460$ & $32.66 \pm 1.853$ & $<0.001$ & & $33.91 \pm 1.440$ & $31.97 \pm 2.037$ & $<0.001$ \\
\hline
\end{tabular}

Data is expressed as mean and standard deviation or as percentage and frequency.

$\mathrm{CI}$ : Confidence interval of the mean difference between both groups.

$p$ is significant when $<0.05$.

Table (5): Intra-operative events and total hospital stay.

\begin{tabular}{llclr}
\hline & $\begin{array}{c}\text { Local group } \\
(\mathrm{n}=82)\end{array}$ & $\begin{array}{c}\text { Systemic group } \\
(\mathrm{n}=82)\end{array}$ & $95 \% \mathrm{CI}$ & $p$ \\
\hline Need for transfusion & $7.3 \%(6)$ & $17.1 \%(14)$ & $-0.01,-0.2$ & 0.056 \\
Hospital stays (hours) & $29.56 \pm 7.350$ & $27.07 \pm 9.944$ & $-0.21,5.18$ & 0.070 \\
\hline
\end{tabular}

Data is expressed as mean and standard deviation or as percentage and frequency.

CI: Confidence interval of the mean difference between both groups.

$p$ is significant when $<0.05$. 


\section{Discussion}

Cesarean section is now the most commonly performed surgery in the world. A recent study documented that Egypt ranked 3 rd among world countries with an estimated rate of Cesarean section of $51.8 \%$ [12] . Delivery by CS is associated with more complications than vaginal delivery. One of the most common complications is postpartum hemorrhage (PPH) being regarded as the leading cause of preventable maternal mortality worldwide [13]. Besides, $\mathrm{PPH}$ is related with the increased rate of blood transfusion and the occurrence of serious anemia. Therefore, it is needed to explore effective approaches to reduce blood loss during and after CS [14]. During placental delivery, fibrinogen and fibrin are rapidly degraded, whereas plasminogen activators and fibrin degradation products increase due to activation of the fibrinolytic system. This activation can last up to $6-10 \mathrm{~h}$ postpartum, causing more bleeding [15].

In this context tranexamic acid (TXA) is a competitive synthetic analog to lysine that reversibly binds to lysine receptor sites in plasminogen, thus preventing the conversion from plasminogen to plasmin and preventing fibrin degradation; it does not affect platelet count, it prevents platelet asthenia, and it does not decrease coagulation parameters such as activated partial thromboplastin time or prothrombin times [16]. It has shown promising results during surgical procedures in patients with hematological disorders [17] and cesarean sections when used intravenously (IV), but some complications have been described [18], such as venous thrombose, seizures, pulmonary embolism, myocardial infarction, strokes, and blood-brain barrier penetration [17], which is a concern in pregnant and parturient ladies. There is a growing interest in administering TXA in a topical fashion, with positive results reported in dental procedures, epistaxis [19], spinal surgery [20] and intraarticular in hip and knee procedures $[21,22]$.

Although previously discussed in the previous surgical procedures, there is a paucity of studies handling the topical application of TXA in the field of obstetrics despite its common use in the same field via other administration routes. This study was conducted at Mansoura University hospitals aiming to evaluate the role of adjunctive IV Tranexamic acid versus its topical infusion of the placental bed for prevention of postpartum hemorrhage. We included a total of 164 pregnant subjects planning for cesarean section who were randomly divided into two groups; the initial group included cases who were subjected to local tranexamic acid administration, and the other group included cases who were commenced on the intravenous form. In our study, the mean age of the included cases was 35.3 and 33.89 years in the local and systemic groups, respectively. No significant difference was noted between the two groups regarding age $(p=0.150)$.

A previous study evaluating the role of TXA in the prevention of bleeding during cesarean section reported that the mean age of the included cases was 30.2 and 29.2 years in the two groups, respectively, which was near to our findings. Also, the previous study reported no significant difference between the two groups regarding that variable $(p=0.239)$ [23] . Another Egyptian study handling the same perspective reported that the included cases had mean age of 26.08 and 26.68 years in the two groups, respectively [24]. It is reasonable varieties of age range in different studies and this is due to difference of the general population characteristics according to the geographical area, even in the same country.

In the current study, no significant difference was noted between the two groups regarding their BMI $(p=0.267)$, which had mean values of 28.49 and $28.98 \mathrm{~kg} / \mathrm{m}^{2}$ in the two study groups, respectively. This is in accordance with a previous study that also negated any difference between the two groups regarding BMI $(p>0.05)$. It had mean values of 31.0 and $31.2 \mathrm{~kg} / \mathrm{m}^{2}$ in the two study groups, respectively [25] .

In our study, the gestational age of the included cases was 36.96 and 36.93 weeks in the same groups, respectively ( $p=0.881)$.

Sanad et al., [24] also reported no significant difference between the two groups regarding their gestational ages $(p=406)$, which had mean values of 38.95 and 38.73 weeks in the two groups, respectively. Another study also confirmed the previous findings [26].

In the current study, previous CS was the commonest indication in both groups, as it was reported in 53.7 and $52.4 \%$ of cases in the local and systemic groups, respectively. Other causes included diabetes, preeclampsia, infertility, abnormal presentation, twin pregnancy, low lying placenta, abnormal liquor, fetal distress, and CPD. Indication for cesarean section was not a significant variable on comparing the two groups. In our center, Mansoura University Hospitals which is considered a tertiary center for the surrounding regions, cesarean section is not "on demand", and it is performed only when there is a clear indication for it. Another Egyptian 
study reported that, the most commonly cited indications were previous CS, 'other', and fetal distress. This study included cases from 13 public hospitals from different Egyptian governorates [27]. That explains the high rate of previous CS in the current study. Based on the previous preoperative data, there was no significant difference between the study groups regarding all of these parameters. This indicates two facts; first, the proper randomization technique performed in this study. Secondly, that should negate any bias that may have skewed the results in favor of one group rather than the other one.

In our study, the mean operative time was 6.59 and 48.48 minutes in the two groups, respectively. No significant difference was detected between the two groups regarding that parameter $(p=0.143)$. This agrees with multiple previous studies that stated that operative time for cesarean section often ranges between 40 and 50 minutes [28,29].

When it comes to blood loss, blood in the suction jar had mean values of 274.7 and 332.32 $\mathrm{ml}$, whereas estimated blood loss had mean values of 691.46 and $746.04 \mathrm{ml}$ in the two groups, respectively. Blood loss was significantly increased in the systemic group versus local group $(p<0.001)$. TXA has been the first choice among hemostatic agents to decrease peri- and postoperative bleeding in various surgical cases [30,31]

Regarding the systemic administration of TXA in CS, it was confirmed by multiple previous studies. Sekhavat et al., [15] reported that IV TXA use was associated with a significant decrease in intraoperative blood loss $(p<0.001)$. Another study confirmed these findings [23]. Furthermore, other authors reported that blood loss in the TXA group intraoperatively was $262.5 \pm 39.6 \mathrm{~mL}$ compared with $404.7 \pm 94.4 \mathrm{~mL}$ in the control group $(p<0.001)$ [32] An additional Egyptian study also confirmed the previous findings as TXA administration was associated with a significant decrease in intraoperative bleeding (2293.6 vs. $328.3 \mathrm{ml}$ in controls) [24] Even in cases with placenta accrete, intraoperative blood loss was significantly lower in the TXA group $2232 \pm 1204 \mathrm{ml}$ compared to the placebo group $3405 \pm 1193 \mathrm{ml}[33]$.

Although the advantages of IV TXA are undeniable, its association with the risk of systemic complications are also not uncommon. It possesses potential risk of thrombosis in predisposed individuals with other rare systemic side effects such as visual disturbances, orthostatic symptoms, headaches, and myoclonus. To negate these undesirable systemic effects, topical route has been introduced and is being studied extensively over the recent past $[21,22,34,35]$

The competitive mechanism of actions of TXA should be effective when applied in topical fashion as it avoids fibrin degradation [36]. According to Astedt et al., [37], TXA acts directly at active bleeding and clot formation sites and not within the circulation. It was previously supposed that This achieves a higher therapeutic concentration at the site of bleeding, effectively limiting blood loss [22]

When administered IV, the half-life is reached within $80 \mathrm{~min}$ and peak plasma concentration is $1 \mathrm{~h}$ after injection [38]. It has high tissue penetration and absorbance as a one-time IV administration of $10 \mathrm{mg} / \mathrm{kg}$ allows for $80 \%$ systemic fibrinolysis inhibition. In a topical fashion, plasma levels are $70 \%$ lower than when used IV [19]

Krhon et al., [39] studied the use of tranexamic acid in orthopedic surgery and reported that by washing the wound with a tranexamic acid solution before closing, the fibrinolytic markers measured in the drain tube were significantly lower in the topical TXA group compared with the non-TXA group. These results suggest that topical TXA acts very quickly, allowing IV infusion to stop sooner and at less cost. In line with our findings regarding the efficacy of topical TXA, a recent study also reported that topical application of TXA was associated with a decrease in intraoperative bleeding (811 vs. 984ml for the IV TXA) [20]. Of course, the discrepancy between the amount of blood loss would vary between studies according to the operation type, surgeon experience, and method of calculating blood loss.

In the same context, in a recent preliminary report, topical administration of TXA was associated with a significant decrease in intraoperative bleeding during face lift surgeries. This led to a significant decrease in operative time and postoperative drain discharge [40].

Rohrich and Cho at 2018 [41] published a review article presenting their preliminary experience with topical TXA in 150 cosmetic surgery patients (blepharoplasty, facelift, rhinoplasty, abdominoplasty, breast augmentation). TXA was diluted to a $3 \%$ concentration and applied to the wound bed for 3 to 5 minutes utilizing gauze, neuro-pledgets, or irrigants. The authors observed reduced intraoperative bleeding and a decrease in postoperative ecchymosis and swelling. In a systematic review by Winter et al., the role of topical TXA has been 
very well established in arthroplasty surgeries providing at least equal benefits of reducing blood loss especially in the postoperative period and minimizing the risk of systemic complications compared with iv TXA [42]

In the current study, although there was no significant difference between the two groups regarding preoperative hemoglobin levels $(p=0.351)$, there was a significant decrease in it in the systemic group ( 9.82 vs. $10.15 \mathrm{gm} / \mathrm{dl}-p=0.001$ ). The same pattern was also noted in the hematocrit value $(p=0.025)$. The change in both hemoglobin and hematocrit levels was significantly higher in the systemic group ( $p=0.008$ and 0.032 respectively). The previous findings confirm the intraoperative blood loss, as the group having more blood loss expressed more significant decrease in both hemoglobin and hematocrit. We liked to confirm the beneficial effect of local TXA versus its systemic use by both blood loss and hematological parameter change. This is due to the fact that estimating blood loss during cesarean deliveries is inaccurate and subjective, due to the admixture with amniotic fluid [25]

In our study, blood transfusion showed no significant difference between the two groups although it was needed in 7.3 and $17.1 \%$ of cases in the two groups, respectively ( $p=0.056)$. Panteli et al., [43] reported seven RCTs and concluded that topical TXA reduced the rate of blood transfusion (RR 2.12 , 95\% CI: 1.19 to 3.84 ). Likewise, local infiltration of TXA is being studied in trauma surgeries where TXA is being given intramuscularly (deep to the fascia) before closure of the wound. Two studies have been identified where local TXA is given in peri-trochanteric fractures $[\mathbf{4 4 , 4 5}]$. Interestingly, results of these studies are contrast to each other with one reporting up to $43 \%$ reduction in transfusion requirement with local TXA and other observing no differences between local TXA and control groups. Reducing operative blood loss would lower the risks and costs associated with blood transfusion. Blood is a scarce resource but even when blood is available, it can transmit potentially fatal viral infections [13].

Our results showed no significant difference between the two groups regarding duration of hospitalization $(p=0.07)$. This was due to the absence of major complications that may cause prolonged recovery at hospital. Also, most women undergoing CS in Egypt are discharged within 48 hours after delivery, which in agreement with our findings. We encourage the use of topical TXA in cesarean section as it is associated with less blood loss and less change in hematological parameters.

\section{Conclusion:}

Based on the previous findings, it is apparent that topical administration of TXA is associated with more effective on blood loss and less change in hematological parameters compared to its intravenous administration.

\section{Limitations:}

Our study has some limitations, first of all, it is a single center study. Also, we should have included a control group to confirm the beneficial effect of its systemic use.

\section{References}

1- NCCEMD S.M.: Mothers 2005-2007: Fourth Report on Confidential Enquiries into Maternal Deaths in South Africa. Pretoria, SA: South African Department of Health, 11-47, 2009.

2- HOGAN M.C., FOREMAN K.J., NAGHAVI M., AHN S.Y., et al.: Maternal mortality for 181 countries, 19802008: A systematic analysis of progress towards Millennium Development Goal 5. The Lancet, 375 (9726): 16091623,2010

3- KHAN K.S., WOJDYLA D., SAY L., GULMEZOGLU A.M., et al.: WHO analysis of causes of maternal death: A systematic review. Lancet, 367 (9516): 1066-1074, 2006.

4- KNIGHT M., CALLAGHAN W.M., BERG C., ALEXANDER S., et al.: Trends in postpartum hemorrhage in high resource countries: A review and recommendations from the International Postpartum Hemorrhage Collaborative Group. BMC Pregnancy Childbirth, 9 (1): 55, 2009.

5- MUNIR S.I., IQBAL R., HUMAYUN S. and CHAUDHARY S.: Indications and Complications of Obstetric Hysterectomy in a Tertiary Care Hospital of Lahore. Annals of King Edward Medical University, 24 (S): 831835,2018

6- OKAMOTO S., HIJIKATA-OKUNOMIYA A., WANAKA K., OKADA Y., et al., editors.: Enzyme-controlling medicines: Introduction : Copyright $\odot 1997$ by Thieme Medical Publishers, Inc., 1997.

7- GROSS J.B., BACHENBERG K.L., BENUMOF J.L., CAPLAN R.A., et al.: Practice guidelines for the perioperative management of patients with obstructive sleep apnea: A report by the American Society of Anesthesiologists Task Force on Perioperative Management of patients with obstructive sleep apnea. Anesthesiology, 104 (5): 1081-1093; quiz 1117-1088, 2006.

8- BUTWICK A.J., GOODNOUGH L.T.: Transfusion and coagulation management in major obstetric hemorrhage. Curr. Opin. Anaesthesiol., 28 (3): 275-284, 2015.

9- FRIMAT M., DECAMBRON M., LEBAS C., MOKTEFI A., et al.: Renal Cortical Necrosis in Postpartum Hemorrhage: A Case Series. Am. J. Kidney Dis., 68 (1): 50-57, 2016. 
10-GARCHA P.S., MOHAN C.V. and SHARMA R.M.: Death after an inadvertent intrathecal injection of tranexamic acid. Anesth. Analg., 104 (1): 241-242, 2007.

11-LECKER I., WANG D.S., WHISSELL P.D., AVRAMESCU S., et al.: Tranexamic acid-associated seizures: Causes and treatment. Annals of Neurology, 79 (1): 18-26, 2016.

12- KANDIL M.: The sky rocketing rate of cesarean section in Egypt. Glob Drugs Therap., 3 (4): 1-1, 2018.

13- BOERMA T., RONSMANS C., MELESSE D.Y., BARROS A.J., et al.: Global epidemiology of use of and disparities in caesarean sections. The Lancet, 392 (10155): 1341-1348, 2018.

14- WANG H.Y., HONG S.K., DUAN Y. and YIN H.M. Tranexamic acid and blood loss during and after cesarean section: A meta-analysis. J. Perinatol., 35 (10): 818-825, 2015.

15- SEKHAVAT L., TABATABAII A., DALILI M., FARAJKHODA T., et al.: Efficacy of tranexamic acid in reducing blood loss after cesarean section. J. Matern Fetal Neonatal Med., 22 (1): 72-75, 2009.

16- ARUN-KUMAR V. and NARESH-BABU J.: Is There a Role for Preoperative Local Infiltration of Tranexamic Acid in Elective Spine Surgery? A Prospective Randomized Controlled Trial Analyzing the Efficacy of Intravenous, Local Infiltration, and Topical Administration of Tranexamic Acid. Global Spine Journal, 2192568219 888446, 2019.

17- FERGUSSON D.A., HEBERT P.C., MAZER C.D., FREMES S., et al.: A comparison of aprotinin and lysine analogues in high-risk cardiac surgery. N. Engl. J. Med., 358 (22): 2319-2331, 2008.

18- WANG M., ZHENG X.F. and JIANG L.S.: Efficacy and Safety of Antifibrinolytic Agents in Reducing Perioperative Blood Loss and Transfusion Requirements in Scoliosis Surgery: A Systematic Review and Meta-Analysis. PLoS One, 10 (9): e0137886, 2015.

19- WINTER S.F., SANTAGUIDA C., WONG J. and FEHLINGS M.G.: Systemic and topical use of tranexamic acid in spinal surgery: A systematic review. Global Spine Journal, 6 (3): 284-295, 2016.

20- WEISSMANN K.A., LAFAGE V., BARRIOS PITAQUE C., LAFAGE R., et al.: Efficacy of topical versus intravenous tranexamic acid in spinal deformity. Eur. Spine J., 29 (12): 3044-3050, 2020.

21- KONIG G., HAMLIN B.R. and WATERS J.H.: Topical tranexamic acid reduces blood loss and transfusion rates in total hip and total knee arthroplasty. J. Arthroplasty, 28 (9): 1473-1476, 2013.

22- ALSHRYDA S., SUKEIK M., SARDA P., BLENKINSOPP J., et al.: A systematic review and meta-analysis of the topical administration of tranexamic acid in total hip and knee replacement. Bone Joint J., 96-B (8): 10051015, 2014.

23- SENTÜRK M.B., CAKMAK Y., YILDIZ G. and YILDIZ P.: Tranexamic acid for cesarean section: A double-blind, placebo-controlled, randomized clinical trial. Arch. Gynecol. Obstet., 287 (4): 641-645, 2013.

24- SANAD Z.F., ELLAKWA H.E., GOMAA A.M., HAMZA H.A., et al.: Effect of tranexamic acid in reducing blood loss during and after cesarean delivery. Menoufia Medical Journal, 33 (4): 1270, 2020.

25- GUNGORDUK K., YILDIRIM G., ASICIOGLU O., GUNGORDUK O.C., et al.: Efficacy of intravenous tranexamic acid in reducing blood loss after elective cesarean section: A prospective, randomized, doubleblind, placebo-controlled study. Am. J. Perinatol., 28 (3): 233-240, 2011.

26- MILANI F., HARYALCHI K., SHARAMI S.H., ATRKARROSHAN Z., et al.: Prophylactic effect of tranexamic acid on hemorrhage during and after the cesarean section. International Journal of Womens Health and Reproduction Sciences, 7 (1): 74-78, 2019.

27- ELNAKIB S., ABDEL-TAWAB N., ORBAY D. and HASSANEIN N.: Medical and non-medical reasons for cesarean section delivery in Egypt: A hospital-based retrospective study. BMC Pregnancy Childbirth, 19 (1): 411, 2019.

28- GAI M.Y., WU L.F., SU Q.F. and TATSUMOTO K. Clinical observation of blood loss reduced by tranexamic acid during and after caesarian section: A multi-center, randomized trial. Eur. J. Obstet. Gynecol. Reprod Biol., 112 (2): 154-157, 2004.

29- GHOSH A., CHAUDHURI P. and MUHURI B.: Efficacy of intravenous tranexamic acid before cesarean section in preventing post partum hemorrhage-a prospective randomized double blind placebo controlled study. Int. J. Bio. Med. Res., 5: 4461-4464, 2014.

30- CAI J., RIBKOFF J., OLSON S., RAGHUNATHAN V., et al.: The many roles of tranexamic acid: An overview of the clinical indications for TXA in medical and surgical patients. Eur. J. Haematol., 104 (2): 79-87, 2020.

31- SENTILHES L., WINER N., AZRIA E., SENAT M.V., et al.: Tranexamic Acid for the Prevention of Blood Loss after Vaginal Delivery. N. Engl. J. Med., 379 (8): 731742, 2018.

32- MOVAFEGH A., ESLAMIAN L. and DORABADI A.: Effect of intravenous tranexamic acid administration on blood loss during and after cesarean delivery. Int. J. Gynaecol. Obstet., 115 (3): 224-226, 2011.

33- IBRAHIM T.H.: Efficacy of tranexamic acid in reducing blood loss, blood and blood products requirements in Cesarian sections for patients with placenta accreta. AinShams Journal of Anesthesiology, 11 (1): 1-6, 2019.

34- HUERFANO E., HUERFANO M., SHANAGHAN K., BARLOW M., et al.: Use of Topical Tranexamic Acid Reduces Direct and Indirect Blood Loss and Transfusion Rates in Revision Total Hip Arthroplasty. HSS J., 16 (Suppl 2): 285-292, 2020.

35- GILBODY J., DHOTAR H.S., PERRUCCIO A.V. and DAVEY J.R.: Topical tranexamic acid reduces transfusion rates in total hip and knee arthroplasty. J. Arthroplasty, 29 (4): 681-684, 2014.

36- JIA J.: Combined use of intravenous and topical tranexamic acid in patients aged over 70 years old undergoing total hip arthroplasty. Journal of orthopaedic surgery and research, 14 (1): 1-7, 2019.

37- ASTEDT B., LIEDHOLM P., WINGERUP L., editors.: The effect of tranexamic acid on the fibrinolytic activity of vein walls. Annales chirurgiae et gynaecologiae, 1978. 
38- ANDERSSON L., NILSSON I.M., NILEHN J.E., HEDNER U., et al.: Experimental and clinical studies on AMCA, the antifibrinolytically active isomer of paminomethyl cyclohexane carboxylic acid. Scand J. Haematol., 2 (3): 230-247, 1965.

39- KROHN C.D., SøRENSEN R., LANGE J.E., RIISE R., et al.: Tranexamic acid given into the wound reduces postoperative blood loss by half in major orthopaedic surgery. The European Journal of surgery Supplement: Acta chirurgica Supplement, (588): 57-61, 2003.

40- FERNAU J.: Commentary on: Local Infiltration of Tranexamic Acid With Local Anesthetic Reduces Intraoperative Facelift Bleeding: A Preliminary Report. Aesthet Surg. J., 40 (6): 594-596, 2020.

41- ROHRICH R.J. and CHO M.J.: The Role of Tranexamic Acid in Plastic Surgery: Review and Technical Considerations. Plast. Reconstr. Surg., 141 (2): 507-515, 2018.
42- WINTER S.F., SANTAGUIDA C., WONG J. and FEHLINGS M.G.: Systemic and Topical Use of Tranexamic Acid in Spinal Surgery: A Systematic Review. Global Spine J., 6 (3): 284-295, 2016.

43- PANTELI M., PAPAKOSTIDIS C., DAHABREH Z. and GIANNOUDIS P.V.: Topical tranexamic acid in total knee replacement: A systematic review and meta-analysis. Knee, 20 (5): 300-309, 2013.

44- DRAKOS A., RAOULIS V., KARATZIOS K., DOXARIOTIS N., et al.: Efficacy of Local Administration of Tranexamic Acid for Blood Salvage in Patients Undergoing Intertrochanteric Fracture Surgery. J. Orthop. Trauma., 30 (8): 409-414, 2016.

45- VIRANI S.R., DAHAPUTE A.A., PANDA I. and BAVA S.S.: Role of Local Infiltration of Tranexamic Acid in Reducing Blood Loss in Peritrochanteric Fracture Surgery in the Elderly Population. Malays Orthop. J., 10 (3): 2630, 2016. 


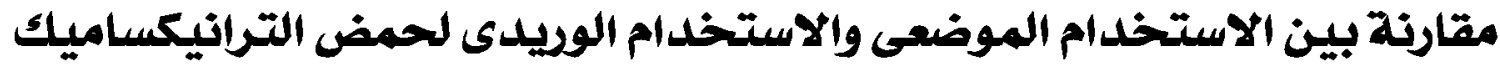 فى العمليات القيصرية الإختيارية الوريلية}

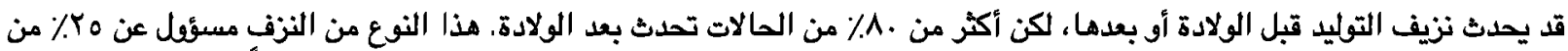

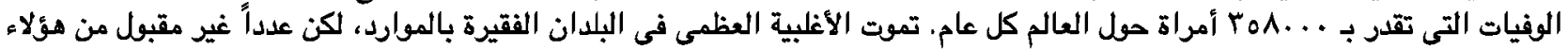
النساء يموت فى البلدان الفنية بالموارد .

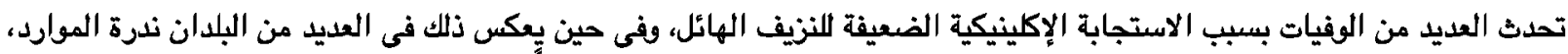

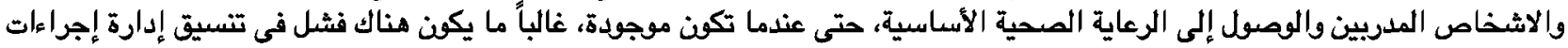

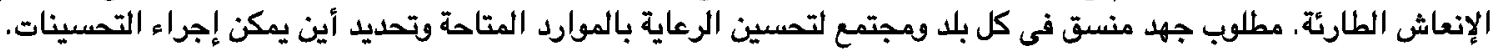

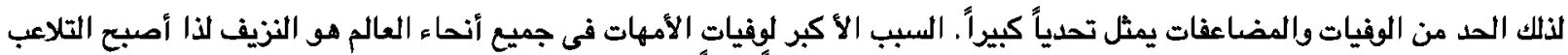

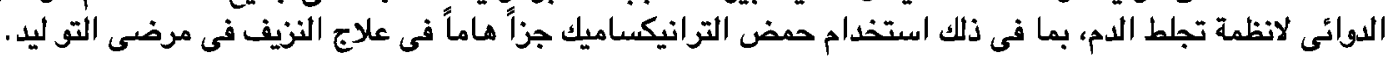

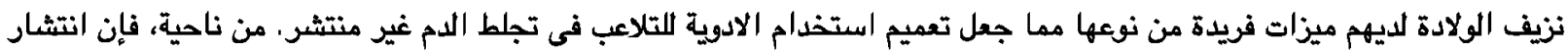

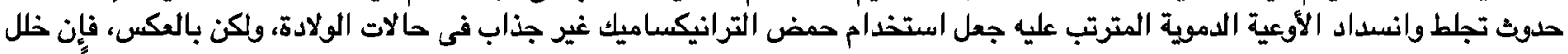

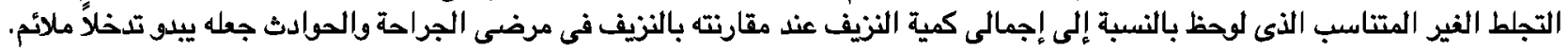

الهدف من الرسالة: لتحديد فعالية وسلامة استخدام حمض الترانيكسامك فى العملية القيصرية الاختيارية خلال الفترة المحيطة بالعمليات

المرضى وطريقة البحث:

- الدراسة: هذه تجرية سريرية عشوائية.

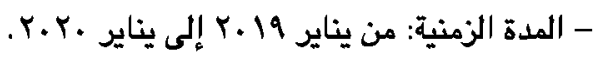

$$
\text { معايير الاشتمال فى البحث: }
$$

ا- السيدات الحوامل فى الثهود الثُلاث الأخيرة من الحمل الذين يخططون لولادة عن طريق ولادة قيصرية إختيارية.

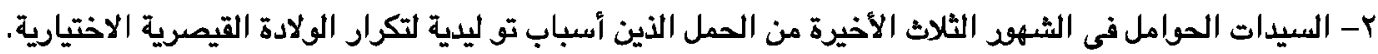

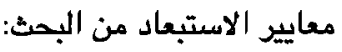

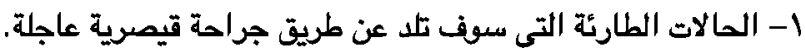

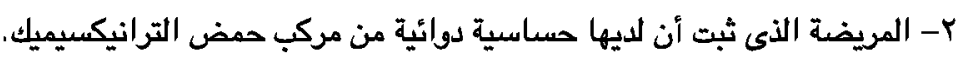

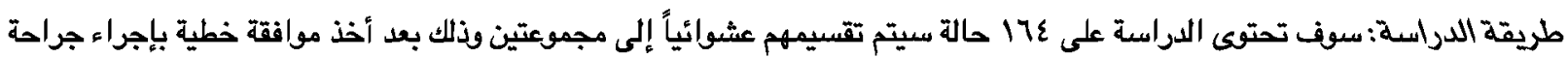

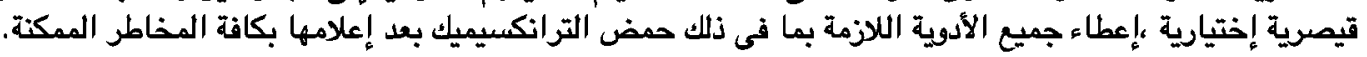

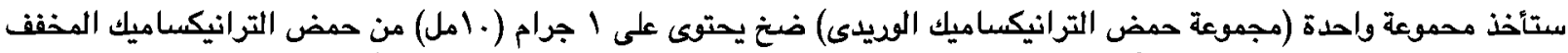

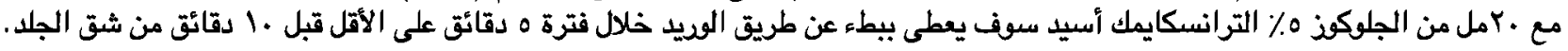

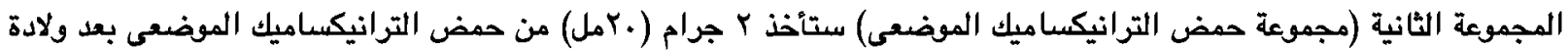

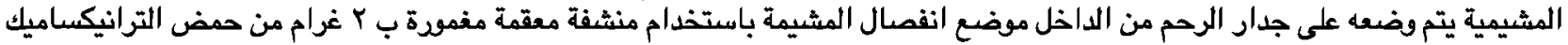

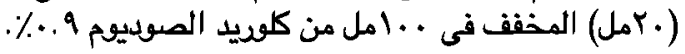

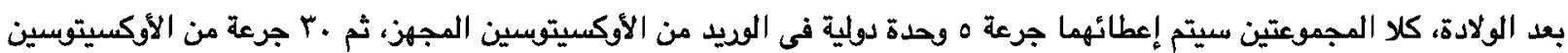

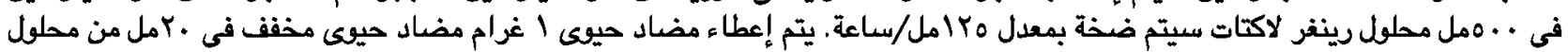
ملحى طبيعى خلال فترة م دقائق.

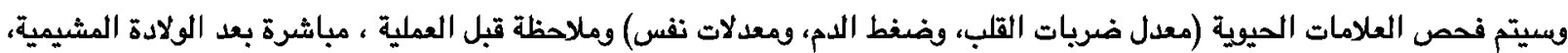

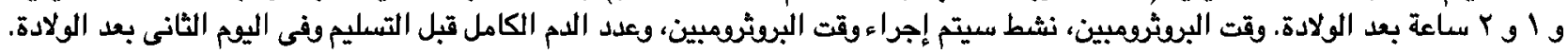
بعد عمل خروج الحالات، فإن النساء اللواتى يتلقين حمض الترانيكساميك سيعطون بطاقة متابعة بها تعليمات حول علامات ألعات وأعراض الجلطات

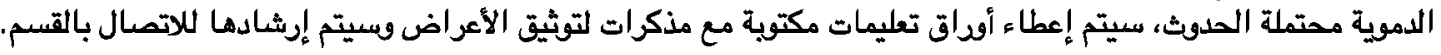

